Available online on 15.06.2020 at http://jddtonline.info
Open Access to Pharmacentical and Medical Research
unrestricted non-commercial use, provided the original work is properly cited

Open Access

Review Article

\title{
Morphology, Phytochemistry and Pharmacological Activity of Vitex negundo: An Overview
}

\author{
Yogendra Singh $^{* 1}$, Pankaj Mishra ${ }^{2}$ and Pushpendra Kannojia ${ }^{1}$ \\ 1 Department of Pharmacology, BIU College of Pharmacy, Bareilly International University, Bareilly-243006, U.P., India \\ ${ }^{2}$ Department of Pharmaceutical Chemistry, Keshlata College of Pharmacy, Bareilly International University, Bareilly-243006, U.P., India
}

\begin{abstract}
Now days a herbal and traditional medicines mostly used in all over the world according to WHO, about 60 to $65 \%$ world population practicing herbal and traditional medicines. Vitex negundo Linn. is an aromatic herb belong to family Verbenaceae. It is also known as Nirgundi, Five leaved chaste tree. Plants have many chemical constituents as flavonoids, volatile oil, triterpenes, diterpenes, sesquiterpenes, lignan, flavones, glycosides, iridoid glycosides and stilbene derivative. These chemical constituents are present in each part of the plant. Vitex negundo extract have various pharmacological activities such as anti-inflammatory, antipyretic, anti-arthritic, antioxidant, analgesic activity, antibacterial activity, antitumor activity, anti-amnesic activity, anxiolytic activity, Nephroprotective activity, anti-HIV activity, Antitubercular activity, antieosinophilic activity, anti-snake venom activity. This review article provides depth information related to plant morphology, cultivation, chemical constitutes, pharmacological activities and their medicinal uses.
\end{abstract}

Keywords: Vitex negundo, Nirgundi, Casticin, Anti-Gout Activity

Article Info: Received 28 March 2020; Review Completed 22 May 2020; Accepted 30 May 2020; Available online 15 June 2020

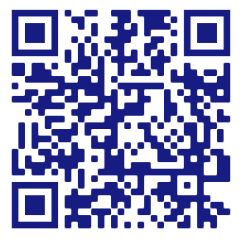

\section{Cite this article as:}

Singh Y, Mishra P, Kannojia P, Morphology, Phytochemistry and Pharmacological Activity of Vitex negundo: An Overview , Journal of Drug Delivery and Therapeutics. 2020; 10(3-s):280-285 http://dx.doi.org/10.22270/jddt.v10i3-s.4173

*Address for Correspondence:

University, Bareilly-243006, Uttar Pradesh, India

\section{INTRODUCTION}

Vitex negundo Linn is a large aromatic shrub (commonly known as Nirgundi, Five leaved chaste tree) belonging to the family Verbenaceae. Almost all the parts of this plant possesses great medicinal values and it is employed as a remedy in various traditional systems of medicine like Ayurveda, Chinese, Siddha and Unani to treat various diseases. 1 In Indian traditional medicine system Vitex negundo Linn is referred as 'sarvaroganivarani'- the remedy for all diseases. A popular local name of the Bengali in the western Himalayan area of India. It is useful in many diseases and eliminates the disease with a brush. A lot of chemicals are found in vitex negundo. Nirgundi in Sanskrit means which protects the body from diseases. ${ }^{2}$

\section{TAXONOMICAL CLASSIFICATION}

$\begin{array}{ll}\text { Kingdom - } & \text { Plantae } \\ \text { Subkingdom - } & \text { Tracheobionta } \\ \text { Super division - } & \text { Spermatophyte } \\ \text { Division - } & \text { Magnoliophyta } \\ \text { Class - } & \text { Magnoliopsida } \\ \text { Subclass - } & \text { Asteridae }\end{array}$

$\begin{array}{ll}\text { Order - } & \text { Lamiales } \\ \text { Family - } & \text { Verbenaceae } \\ \text { Genus - } & \text { Vitex } \\ \text { Species - } & \text { negundo }^{3}\end{array}$

\section{VERNACULAR NAMES}

Assamese - $\quad$ Aslok, Pochatia

Bengali - $\quad$ Beguna, Nishinda,

Hindi -

Nirgundi, Sambhalu,

Kannada - Karilakki, Lakkagida,

Malyalam - Karunocci, Noch-chi,

Marathi - $\quad$ Nirgunda, Nengar,

Oriya -

Thingkhawilupa, Niligundi.

Sanskrit - $\quad$ Nirgundi, Sindhuvara

Tamil -

Nallanocci,Nochi,

Telgu - Nallavavili, Sindhuvaruma,

Urdu - Sambhalu, Tukhmsambhalu. 4 


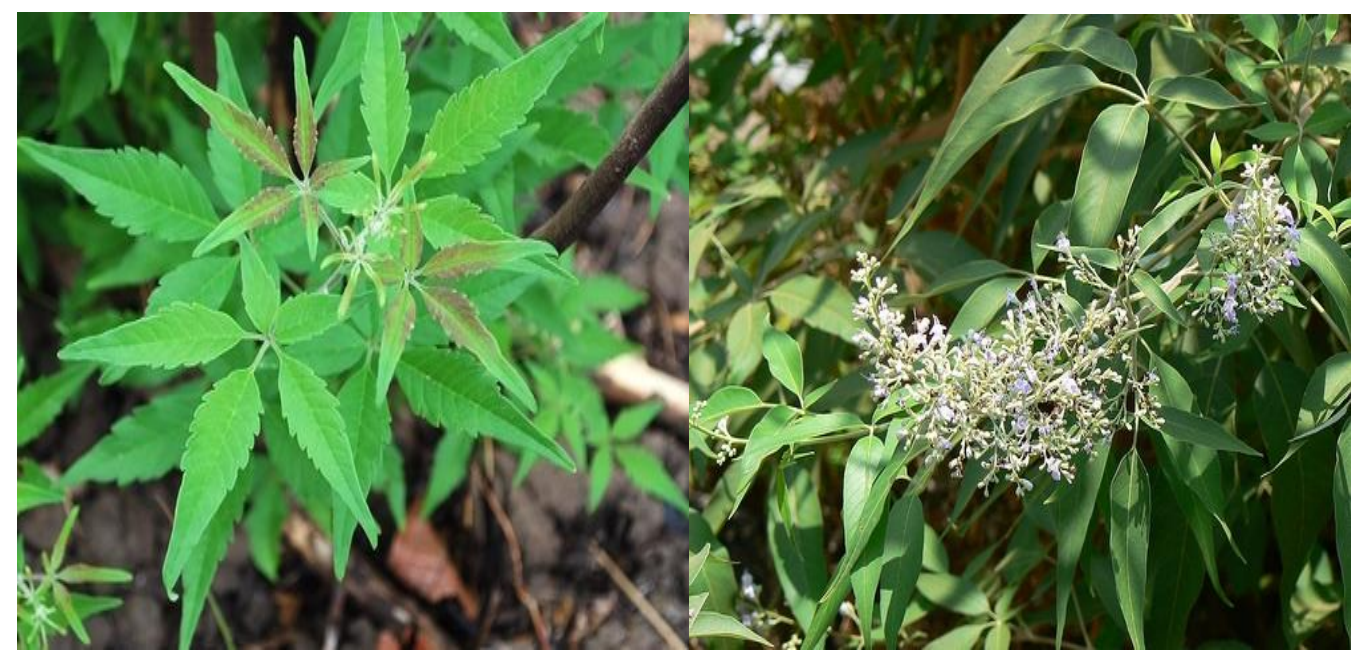

Figure 1: Vitex negundo leaves

\section{PLANT DESCRIPTION}

Vitex negundo Linn is a woody, erect and large aromatic deciduous shrub which grows to small tree of height 2-8 min height. The bark is usually reddish brown. ${ }^{5}$ The leaves are penta foliate and the leaflets are arranged palmately and terminal leaflets are long $(4-10 \mathrm{~cm})$ acute with petiolate(1-
1.3 long), lanceolate, hairy beneath and both the ends are pointed. ${ }^{6}$ The flowers are numerous which are bluish purple in colour and in branched in tomatoes cymes and the fruits are round, succulent and black on ripening with four seeds. 7

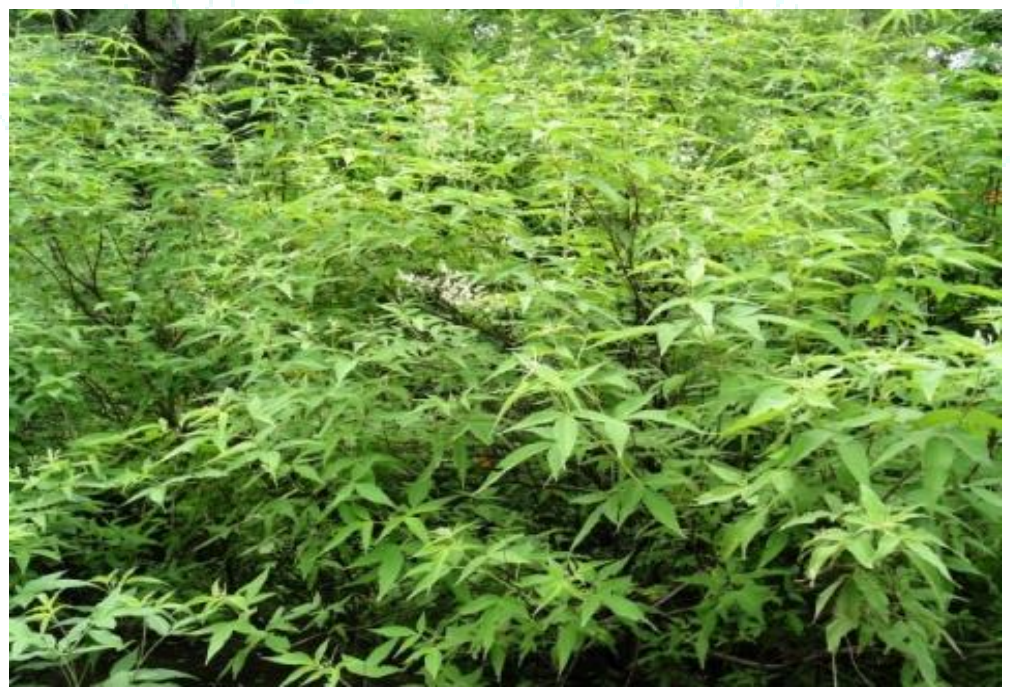

Figure 2: Whole Plant of Vitex negundo

\section{GEOGRAPHICAL DISTRIBUTION:}

It grows in humid places or along water courses in wastelands and mixed open forests and globally distributed in Afghanistan, Pakistan, India, Shri Lanka, Thailand, Malaysia, Eastern Africa and Madagascar, America, Europe, China and West Indies. ${ }^{8}$

\section{PHYTOCHEMICAL CONSTITUENTS:}

In Preliminary phytochemical study of the extract was analysis for the presence of volatile oil, triterpenes, diterpenes, sesquiterpenes, lignan, flavonoids, flavones, glycosides, iridoid glycosides and stilbene derivative. ${ }^{1,9}$ The detailed of phytochemical constituents is present in each part of the plant is given below.

\section{Leaves:}

The various chemical constituents present in leaves of Vitex negundo Linn leaves are Friedelin, vitamin-C, carotene, casticin, artemetin, terpinen-4-ol, $\alpha$-terpineol, sabenine, globulol, spathulenol, $\quad \beta$ - farnesene, farnesol, bis(1,1dimethyl) methylphenol, $\alpha$-pinene, $\beta$-pinene, linalool, terpinyl acetate, caryophyllene epoxide, caryophyllenol, vitexicarpin, viridiflorol, 4,4"- dimethoxy-trans-stilbene, 5,6,7,8,3'4'5- heptamethoxy, 5-hydroxy-6,7,8,3'4'pentamethoxy (5-Odesmethylnobiletin), 5-hydroxy6,7,8,3',4',5-hexamethoxy(gardeninA), 5-hydroxy-6,7,8,4'tetramethoxy (gardeninB), 5- hydroxy-7,3',4',5'tetramethoxyflavone (corymbosin), terpinen-4-ol, $\alpha$ copaene, $\beta$-caryophyllene, $\beta$-elemene, camphene, $\alpha$-thujene, $\alpha$-pinene, sebinene, linalool, stearic acid and behenicacid, $\alpha$ elemene, $\delta$ - elemene, $\beta$-elemene, $\beta$-eudesmol, camphor, camphene, careen, 1,8- cineol, 1-oceten-3-ol, $\gamma$-terpinine, $\alpha$ phellendrene, $\beta$-phellendrene, $\alpha$ - guaiene, abieta-7,13-diene, neral, geranial, bornyl acetate, nerolidol, $\beta$-bisabolol, cedrol, 2'-p-hydroxybenzoyl mussaenosidic acid, agnuside, lagundinin, aucubin viridiflorol, squalene, 5-hydroxy3,6,7,3',4'- pentamethoxy flavone, 5-hydroxy-3,7,3',4'tetramethoxy flavones, 5,3-Dibutanoyloxy 3,6,7,4tetramethoxyflavone,5,3'-Dipenty4enoyloxy-3,6,7,4 tetra methoxyflavone, 5,3-Dihexanoyl 3,6,7,4-tetramethoxy flavone, betulinic acid, ursolic acid, dimethoxyflavonone, 
5,3'-dihydroxy-7,8,4'-trimethoxy flavonone, 7,8-Dimehyl herbacetin-3-rhamnoside, vitegnoside, 1,4a,5,7a tetrahydro $1 \beta$ Dglucosyl(3',4'dihydroxybenzoyloxymethyl)-5- ketocyclopenta pyran-4-carboxylic acid, luteolin-7-0- $\beta$-Dglucosid, 6'-p-hydroxybenzoylmussaenosidic acid.<smiles>COc1ccc(-c2oc3cc(OC)c(OC)c(O)c3c(=O)c2OC)cc1O</smiles>

Casticin<smiles>O=c1cc(-c2ccc(O)c(O)c2)oc2cc(O)c(C(O)COCC(O)CO)c(O)c12</smiles>

Isoorientin<smiles>O=c1cc(-c2ccc(O)c(O)c2)oc2cc(O)cc(O)c12</smiles>

Luteolin

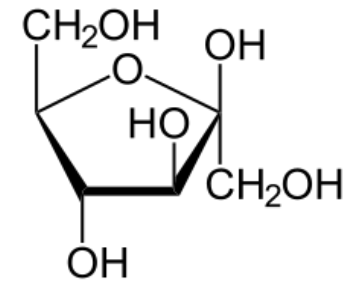

D-Fructofuranose<smiles>C=C1CC[C@@]2(C(C)C)CCC1C2</smiles>

Sabinene<smiles>C=C1CC/C=C(/C)CC[C@@H]2C(C)C[C@H]1C2C</smiles>

Caryophyllene<smiles>CC1=CC[C@@](O)(C(C)C)CC1</smiles>

Terpinen-4-ol

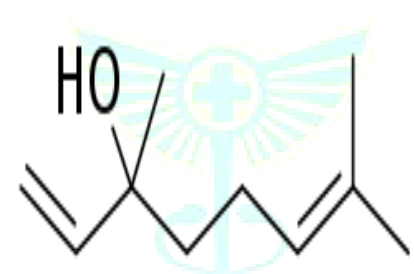

Linalool<smiles>O=C(O)c1ccc(O)cc1</smiles>

4-Hydroxybenzoic acid

Figure 3: Different chemical constituents of Vitex negundo leaves

\section{Seeds}

The seeds of Vitex negundo Linn have chemical constituents such as n-Tritriacontane, n-hentriacontanol, nhentricontane, n-nonacosane, $\beta$-sitosterol, phydroxybenzoic acid and 5oxyisophthalic acid, 3, 4-dihydroxybenzoic acid, artemetin, $3 \beta$-acetoxyolean-12-en-27-oic acid, 5 $\beta$-hydro-8,11,13abietatrien- $6 \alpha$-ol, $\quad 2 \alpha, 3 \alpha$-dihydroxyoleana-5,12-dien-28oicacid, $2 \beta, 3 \alpha$-diacetoxyoleana-5,12-dien-28-oicacid and $2 \alpha, 3 \beta$-diacetoxy-18-hydroxyoleana-5,12-dien-28-oic acid, vitedoin $A$, vitedoamine $A$, vitedoin $B, 5,7,3$ '-trihydroxy 6,8,4'-trimethoxy, 6-hydroxy-4-(4-hydroxy-3- methoxyphenyl)-3-hydroxymethyl-7-methoxy-3, 4- dihydro-2naphthaldehyde.

\section{Stem and bark}

The various chemical constituents present in the stem and bark are 3,6,7,3',4'-Pentamethoxy-5-Oglucopyranosyl rhamnoside, vitexin cafeate, $\beta$-amyrin, epifriedelinol and oleanolic acid, Hepta methyl-phenyl-cyclotetrasiloxane, Cycloheptasiloxane, tetradecamethyl Nona methyl, phenylcyclopentasiloxane, Cyclooctasiloxane, hexadeca methyl, Borazine, 2,4,6-tripheny-l1, 3,5-tryophl, Tetracosamethyl cyclododecasiloxane, pentamethyl phenyl-Disilane, Heptasiloxane, Octadecamethyl, cyclononasiloxanes Cyclooctasiloxane, hexadeca methyl, p-hydroxy benzoic acid, $\beta$-sitosterol, 5-hydroxy-3,6,7,3'4'-pentamethoxy flavone, $3 \beta$ - acetoxy-olean-12-en-27-oic acid, 3ß-hydroxy-olean-5, 12dien-28-oic acid.

\section{Roots}

Vitexoside, agnuside, R-dalbergiphenol, negundin A, negundin B, 6-hydroxy-4-(4-hydroxy-3-methoxy)-3hydroxymethyl-7-methoxy-3,4-dihydro-2-naphthaledehyde, vitrofolal E, (+)-lyoniresinol, (+)-(-)-pinoresinol, and (+)diasyringaresinol, $2 \beta, 3 \alpha$-diacetoxyoleana-5,12-dien-28-oic acid; $2 \alpha, 3 \alpha$-dihydroxyoleana-5,12-dien-28-oic acid, $2 \alpha, 3 \beta$ diacetoxy-18-hydroxyoleana-5,12-dien-28-oic acid, vitexin and isovitexin, acetyl oleanolic acid, sitosterol, 3-formyl-4.5dimethyl-8-oxo-5H-6,7-dihydronaphthofuran (a new furanoeremophilane).

\section{Essential oil of fresh leaves, flowers and dried fruits}

The various chemical constituents of essential oil of from leaves, flowers and dried fruits are $\delta$-guaiene, guaia-3,7dienecaryophyllene epoxide, ethyl-hexadecenoate; $\alpha$ selinene, germacren-4-ol; caryophyllene epoxide, (E)nerolidol, $\beta$-selinene, $\alpha$-cedrene, germacrene $D$, hexadecanoic acid, p-cymene and valencene, viridiflorol(19.55\%), $\beta$-caryophyllene (16.59\%), sabinene (12.07\%), 4-terpineol (9.65\%), $\gamma$-terpinene $(2.21 \%)$, caryophylleneoxide (1.75\%), 1-oceten-3-ol (1.59\%), and globulol (1.05\%). . $^{10,11,12,13,14}$ 


\section{PHARMACOLOGICAL ACTIVITIES}

\section{Anxiolytic Activity:}

Sharma A et al., 2018 investigated the anxiolytic activity of different parts, i.e. leaves, stems and roots of $V$. negundo by different solvents as like petroleum ether, chloroform, ethanol and aqueous extract of Vitex negundo for anxiolytic activity using elevated plus maze model. Among the different parts compared, only the roots showed significant antianxiety activity. Chloroform and ethanol extracts of the roots showed maximum significant antianxiety activity, compared to that of diazepam. ${ }^{15}$

Adnaik RS et al., 2008 anxiolytic activity of an ethanolic extract prepared from the roots of Vitex negundo using the elevated plus maze and light-dark exploration test in mice. Diazepam and the Vitex negundo extractsdo not produced any overt motor dysfunction. These results indicate that Vitex negundo is an effective anxiolytic agent. In conclusion, the actionof extract upon the anxiety models. 16

\section{Analgesic}

Yasmeen A. et al., 2017 evaluated both the peripheral and central analgesic activity of ethanolic extract of Vitex negundo flowers in experimental animals. This activity was evaluated for peripheral analgesic activity by the acetic acid induced writhing test and central analgesic activity by the tail flick method respectively using aspirin as the standard drug. This study showed that the increased analgesic effects which was comparable with that of the standard drug aspirin at in writhing test and produced greater analgesic activity than that of standard drug aspirin at dose in tail flick method. 17

\section{Antitubercular Activity}

Ladda PL et al., 2016 investigated the focused on identification, isolation, characterization of lead constituents and to determine the Antitubercular activity of their isolated compounds by nitrate reductase assay method. The leaves extract with ethanol by soxhlet extraction and ethanol extract separated in petroleum ether, chloroform and methanol. The petroleum ether and chloroform fractions of ethanol extract which contains shows anti- tuberculosis activity. This study showed that the ethanolic extract with significant anti-tubercular activity. 18

\section{Nephroprotective Activity}

Janakiraman M et al., 2015 investigated the Nephroprotective activity of methanolic extracts of Vitex negundo leaves extract on nephrotoxicity induced by cisplatin in male albino rats. This study showed that the methanolic extracts of Vitex negundo treated group also showed an increased in levels of Hb, RBC, WBC, PCV, MCV and MCHC when compared to cisplatin treated rats. The results of this study were concluded that Vitex negundo protected the rats from the deleterious effects of cisplatin. 19

Kumar GS et al., 2011 studies the Nephroprotective activity of methanolic extracts of Vitex negundo bark against chemical induced kidney damage by single oral administration of paracetamol in male Wistar rat. The studied by assessing the biochemical parameters such as serum glutamate pyruvate transaminase, serum glutamate oxaloacetate transaminase, alkaline phosphatase, Bilirubin, total protein and enzymatic antioxidants. This study showed that significant reduction on biochemical parameters as well as enzymatic and non-enzymatic antioxidants when compared to the paracetamol induced kidney toxicity. The result showed that the methanolic extract of Vitex negundo bark has protected the kidney from paracetamol induced toxicity. 20

\section{Anti-Inflammatory activity}

Gangwar AK et al., 2015 investigated anti-inflammatory effect of ethanolic roots extract of Vitex negundo action was studied by Plethysmometer method. It is observed that the ethanolic roots extract of Vitex negundo showed more considerable anti-inflammatory effect by using carrageenan induced rat paw edema method. 21

Singh $\mathbf{P}$ et al., 2009 evaluated anti-inflammatory activity of ethanolic roots extract of Vitex negundoby carrageenan induced rat paw oedema method for acute inflammation. The ethanolic extract of vitex negundo has showed related activity to that of standard drug. This study showed that the ethanolic extract exhibited remarkable anti-inflammatory activity to standard drug of Indomethacin. 22

\section{Anti-Snake Venom activity}

Durairaj B et al., 2014 observed the anti-snake venom activity of hydroethanolic extracts of Vitex negundo leaves. The study showed that blue leaf extract of Vitex negundo has more potent antioxidant and anti-snake venom neutralizing effect. 23

Alam MI et al., 2003 investigated the anti-snake venom activity of root extract of Vitex negundo This plant extract significantly antagonized the vipera russellii and najakaouthia venom. The observed confirmed that the plant extracts possess potent snake venom neutralizing capacity and need further investigation. 24

\section{Antieosinophilic activity}

atel JI et al., 2013 studies the antieosinophilic activity of petroleum ether leaves extract of Vitex negundo in guinea pig by using egg-albumin induced antieosinophilic activity. This study showed that petroleum ether extract of Vitex negundo reduce bronchial hyper responsiveness, asthma and various inflammation, immunology, allergy diseases. 25

\section{Antibacterial activity}

Kamruzzaman M et al., 2013 evaluated the antibacterial activity of Vitex negundo leaves extracts in water and methanol. Vitex negundoleaves were evaluated against enteric bacterial pathogens by using standard disc diffusion, viable bacterial cell count methods, the first time we showed that methanol extract of Vitex negundoleaves exhibited strong bactericidal activity both in-vitro and in-vivo conditions. ${ }^{26}$

Chowdhury JA et al., 2009 studies the antibacterial activity of methanol crude extract of Vitex negundo using kupchan method, disc diffusion method and brine shrimp lethality bioassay respectively. It is observed that the methanolic extract of Vitex negundo showed more prominent zone of inhibition against a number of bacterial and fungal activity. It is a compared to the standard drug. ${ }^{27}$

\section{Antipyretic activity}

Miskin $\mathbf{N}$ et al., 2012 to investigate the antipyretic activity of leaf extracts of Vitex negundo Linn by using yeast induced pyrexia model in Wistar Albino rats. The data obtained indicate that the Petroleum ether and Methanolic extracts of a leaves of Vitex negundo, through per oral route showed the significant reduction in yeast provoked elevated temperature. Both petroleum ether extract and methanolic extract showed significant antipyretic activity. 28

Tirumalasetty J et al., 2012investigated the antipyretic activity of alcoholic extract of Vitex negundo in PGE1 induced 
pyrexia in Albino rats. It is observed that the ethanolic leaves extract of Vitex negundo shows more considerable antipyretic effect by using pyrexia models and hyperpyrexia model in albino rats. 29

\section{Anti HIV Activity}

Kannan M et al., 2012 observed the activity of ethanolic leaf extract of Vitex negundo against HIV-1 Reverse Transcriptase and to identify and quantify the flavonoids present. The plant Vitex negundo ethanolic leaf extract exhibited the most notable activity of $92.8 \%$ against HIV-1 Reverse Transcriptase. This analysis revealed the presence of steroids, triterpenes, alkaloids, flavonoids, antroquinone glycosides and amino acids. Approximately seven flavonoids tested, six were identified in the decreasing order of quantity as kaempherol, myricetin, quercetin, quercetagetin, isorhamnetin and Luteolin. This study showed that the plant Vitex negundo leaf possess anti-reverse transcriptase substances and probably the flavonoids act as anti-virus agents. 30

\section{Anti-Arthritic activity}

Ahirrao R. A et al., 2012 studies the anti-arthritic property of petroleum ether and fresh aqueous extracts of leaves of Vitex negundo ware studied for anti-arthritic activity against formalin induced arthritis in Wister albino rats of either sex. Both the extracts were found to significantly inhibit the paw edema induced arthritis by formalin induced in rats. The results indicate that aqueous extract of Vitex negundo Linn. Leaves had significant anti-arthritic property when compared with the standard and untreated control. 31

Petchi RR et al., 2011 studies the anti-arthritic effect of ethanolic extract of leaves of Vitex negundo in male albino Wistar rats using Freund's complete adjuvant model. The leaves were extracted with petroleum ether by hot percolation method. The male Wistar rats were used for the chronopharmacological and anti-arthritic study. This study concluded that the leaves extracts of Vitex negundo showed significant anti-arthritic activity against Freund's complete adjuvant-induced arthritis in male Wistar rats. 32

\section{Anti-Amnesic activity}

Kanwal A et al., 2010observed the anti-amnesic activity of aqueous extract of Vitex negundo in scopolamine induced amnesia in rats. The aqueous extract of Vitex negundo has showed related activity to that standard drug. This study demonstrates that aqueous Vitex negundo extract has potential therapeutic effects on improving the anti-amnesic activity in rats through inhibiting lipid peroxidation, augmenting endogenous antioxidant enzymes and decreasing acetyl cholinestrase activity in brain. 33

\section{Antitumor activity}

Chitra V. et al., 2009investigated the antitumor activity of the ethanolic extract of leaves of Vitex negundo has been evaluated against Dalton's ascetic lymphoma in Swiss albino mice. This study was increased the life span to assess tumor volume, tumors cell count, viable tumors cell count, mean survival time. The result increased that ethanolic leaves extract of Vitex negundo had more significant antitumor activity when compare with the standard drug. ${ }^{34}$

\section{Antioxidant activity}

Kulkarni RR et al., 2008 evaluated the excellent antioxidant potential activity of methanolic extract also exhibited a strong free radical scavenging activity by 1,1-diphenyl-2picrylhydrazyl method and caused a significant reduction. The formation of thiobarbituric acid binding the substances when evaluated forthe lipid peroxidation inhibitory in antioxidant activity. 35

\section{TRADITIONAL MEDICINAL USE}

It is widely used in folk medicine, particularly in South, Southeast Asia, India and many others country used this plant. Vitex negundo is used for treating stored garlic pests as a cough remedy in the Philippines. It is also used to control mosquitoes. In Malaysia, it is used in traditional herbal medicine for women's health, including treatments for regulating the menstrual cycle, fibrocystic breast disease and post- partum remedies. It has antiseptic, astringent, antiinflammatory and antipyretic properties. 36

\section{CONCLUSION}

Nirgundi is a chief medicine of traditional system as well as Ayurveda. Almost all parts of the plant are use in preparing herbal medicines. The plant is known to possess anticancer, antimicrobial, antifeedant, anti-inflammatory, antihyperpigmentation, hepatoprotective, antihistaminic, analgesic and related activities. This review attempts to encompass the available literature on Vitexnegundo with respect to its traditional uses, chemical constituents and summary of its various pharmacological activities. Vitex negundo possesses numerous biological activities proved by many experimental studies. It represents a class of herbal drug with very strong conceptual base for its use. Thus, this plant has great potential to be developed as a drug by pharmaceutical industries, but before it recommending it for clinical use in these conditions, there is a need to conduct clinical trials and prove its clinical utility.

\section{REFERENCES}

1. Rastogi T, Kubde M, Farooqui IA and Khadabadi SS. A review on ethnomedicinal uses and phyto-pharmacology of antiinflammatory herb Vitex negundo. International Journal of Pharmaceutical Sciences and Research, 2017; 1(1):1-4.

2. Suva MA. A Brief Review on Vitex negundo Linn: Ethnobotany, Phytochemistry and Pharmacology. Invention Journals, 2014; $1: 1$

3. Ullah Z, Ullah R, Shah AHA, Ahmad J and Haider S. Phytochemical and Biological Evaluation of Vitex Negundo Linn: A Review. International Journal ofPharmaceutical Sciences and Research, 2017; 1(1):1-15.

4. Sachin KB, Atul GG and Karunakar GV. A Critical review on sinduvara(Vitex negundo) with special reference to vishachikitsa. International Journal of Ayurveda and Pharma Research, 2017; 5(7):67-73.

5. Rana S and Rana KK. Review on Medicinal Usefulness ofVitex negundo Linn. Open Access Library Journal, 2014; 1:1-13.

6. Gill BS, Mehra R, Navgeet and Kumar S. Vitex negundo and its medicinal value. Molecular Biology Reports, 2018; 45(6):01-10.

7. Ahmed SS and Fatima L. Sanbhaloo (Vitex negundo): Pharmacological Actions and Therapeutic Benefits: A Review. The Pharma Innovation Journal, 2018; 7(9):330-336.

8. TandonVR. Medicinal uses and biological activities of Vitex negundo.Natural Product Radiance, 2005; 4(3):162-165.

9 Fauziya B, Sharma HP, Firdaus S, Jain P and Ranjan A. A review of ethnomedicinal plant-Vitex negundo Linn. International Journal of Advanced Research, 2014; 2(3): 882-894.

10. Venkateswarlu K. Vitex negundo: Medicinal Values, Biological Activities, Toxicity Studies and Phytopharmacological Actions. International Journal of Pharmaceutical and Phytopharmacological Research, 2012; 2(2):126-133.

11. Tiwle R andSanghi DK. Comprehensive Study of Nirgundi Plant: A Survey Report. Journal of Innovations in Pharmaceuticals and Biological Sciences, 2015; 2(2): 125-130.

12. Bano U, Jabeen A, Ahmed A and Siddiqui MA. Therapeutic Uses of Vitex Negundo. World Journal of Pharmaceutical Research, 2015; 4(12):589-606.

13. Suganthi $\mathrm{N}$ and Dubey S. Phytochemical constituents and pharmacological activities of Vitex negundo Linn. Journal of Chemical and Pharmaceutical Research, 2016; 8(2):800-807. 
14. Vishwanathan AS and Basavaraju R. A Review on Vitex negundo Linn.-A Medicinally Important Plant,2010; 3(1):30-42.

15. Sharma A, Gulsheen, Kumar A and Sharma A. Comparative AntiAnxiety Potential of Different Parts of Vitex Negundo Linn. International Journal of Pharmaceutical Sciences and Research, 2018; 1 -7.

16. Adnaik RS, Pai PT, Sapakal VD, Naikwade NS and Magdum CS. Anxiolytic activity of Vitex negundo Linn. in experimental models of anxiety in mice. International Journal of Green Pharmacy, 2009; 243-247.

17. Yasmeen A, Maniyar and Sriraj D. Peripheral and central analgesic activity evaluation of ethanolic extract of Vitex Negundo flowers in experimental animals. International journal of basic and clinical pharmacology, 2017; 611 .

18. Ladda PL andMagdum CS. Antitubercular Activity and Isolation of Chemical Constituents from plant Vitex negundo Linn. Iranian Journal of Pharmaceutical Research, 2016; 17 (4):1353-1360.

19. Janakiraman $M$ and Jeyaprakash K. Nephroprotective effect of Vitex negundo linn. on cisplatin induced nephrotoxicity in male albino rats. World Journal of Pharmaceutical Sciences, 2015; 3(4):706-715.

20. Kumar GS, Lalitha VA, Sengottuvelu S, Sharif SH and Kumar TS. Nephroprotective activity of Vitex negundo linn bark against chemical induced toxicity in experimental rats. International Journal of Advances in Pharmaceutical Sciences, 2011; 2: 5-6.

21. Gangwar AK, Ghosh AK and Saxena V. Anti-inflammatory activity of ethanolic extract of Vitex negundo linn roots. International Journal of Herbal Medicine, 2015; 2 (6):01-02.

22. Singh P, Mishra G, Garg VK, Khosa RL and Kumar A. AntiInflammatory Activity of Vitex Negundo Root Extract. Pharmacology online, 2009; 2:772-781.

23. Durairaj B, Muthu SK and Shreedhar K. In vitro antivenom and antioxidant potential of Vitex negundo leaves (green and blue) against Russell's viper (Daboiarusselli) and Indian cobra (Najanaja) venom. European Journal of Experimental Biology, 2014; 4(4):207-219.

24. Alam MI and Gomes A. Snake venom neutralization by Indian medicinal plants (Vitex negundo and Emblica officinalis) root Extracts. Journal of Ethnopharmacology, 2003; 86(1):75-80.

25. Patel JI and Deshpandey SS. Antieosinophilic activity of various subfractions of leaves of Vitex negundo. International Journal of Nutrition, Pharmacology, Neurological Diseases, 2013; 3(2):135141.

26. Kamruzzaman M, Bari SMN and Shah MF. In vitro and in vivo bactericidal activity of Vitex negundo leaf extract against diverse multidrug resistant enteric bacterial pathogens. Asian Pacific Journal of Tropical Medicine, 2013; 352-359.

27. Chowdhury JA, Islam MS, Asifuzzaman SK and Islam MK. Antibacterial and cytotoxic activity screening of leaf extracts of Vitex negundo. Journal of Pharmaceutical Sciences and Search, 2009; 1(4):103-108.

28.Miskin N, Manjunath KP, Bhandarkar A, Girish B and Manjunatha SK. Antipyretic activity of Vitex negundo Linn Leaves extracts. Rajiv Gandhi University of health sciences journal of pharmaceutical sciences, 2012; 2(2):78-81.

29. Tirumalasetty J, Sheikh U, Chandrasekhar N, Kishan PV and Rasamal K. Evaluation of Antipyretic Activity of Alcoholic Extract of Vitex negundo Leaves in PGE1 induced pyrexia model in Albino Rats. Journal of Chemical and Pharmaceutical Research, 2012; 4(6):3015-3019.

30. Kannan M, Rajendran P, Vedha V, Gnanasekaran A, Shanmugam A and Nair PCR. HIV-1 reverse transcriptase inhibition by Vitex negundo leaf extract and quantification of flavonoids in relation to anti-HIV activity. Journal of Cell and Molecular Biology, 2012; 10(2):53-59.

31. Ahirrao RA and Patel MR. Anti-arthritic Activity of Vitex negundo Linn. Leaves. Asian Journal of Research Chem, 2012; 5(7):843845.

32. Petchi RR, Vijaya C, Parasuraman S, Natchiappan A and Devika GS. Anti-arthritic effect of ethanolic extract of leaves of Vitex negundo Linn. (Verbenaceae) in male albino Wistar rats. International Journal of Research in Pharmaceutical Sciences, 2011; 2(2):213-218.

33. Kanwal A, Mehla J, Kuncha M, Naidu VGM, Gupta YK and Sistla RK. Anti-Amnesic Activity of Vitex Negundo in Scopolamine Induced Amnesia in Rats. Pharmacology \& Pharmacy, 2010; 1:18.

34. Chitra V, Sharma SN and Kayande N. Evaluation of Anticancer Activity of Vitex negundo in Experimental Animals: An in-vitro and in-vivo Study. International Journal of Pharmtech Research, 2009; 1(4):1485-1489

35. Kulkarni RR, Virkar AD and Priscilla D. Antioxidant and Antiinflammatory Activity of Vitex negundo. Indian Journal of Pharmaceutical Sciences, 2008; 70(6):838-840.

36. Roqaiya M, Begum $\mathrm{W}$ and Majeedi SF.A review on Unani traditional uses of sambhaluin females as well as phytochemical and pharmacological properties. International Journal of Pharmaceutical Sciences and Research, 2017; 1-8. 